\title{
Novos táxons e novo registro em Hemilophini (Coleoptera: Cerambycidae: Lamiinae)
}

\author{
Ubirajara R. Martins ${ }^{1,3} \&$ Maria Helena M. Galileo ${ }^{2,3}$ \\ ${ }^{1}$ Museu de Zoologia, Universidade de São Paulo. Caixa Postal 42494, 04218-970 São Paulo, São Paulo, Brasil. \\ 2 Museu de Ciências Naturais, Fundação Zoobotânica do Rio Grande do Sul. Caixa Postal 1188, 90001 -970 Porto Alegre, \\ Rio Grande do Sul, Brasil. \\ ${ }^{3}$ Pesquisador do CNPq.
}

\begin{abstract}
New taxa and new record of Hemilophini (Coleoptera: Cerambycidae: Lamiinae). New species described and illustrated: Adesmus nigrolineatus sp. nov. from Mexico (Oaxaca). From Costa Rica: A. moruna sp. nov. (Heredia); Corcovado bezarki sp. nov. (Guanacaste); Alampyris fuscus sp. nov. (Guanacaste), Cariua gen. nov. type species C. sulphurea sp. nov. (Guanacaste). From Bolivia: Phoebemima albomaculata sp. nov. (Cochabamba); Ipepo gen. nov. type species I. dilatatus sp. nov. (Santa Cruz). From Brazil: Adesmus facetus sp. nov. and Canarana arguta sp. nov. (Rondônia). A new record from Costa Rica of Piruanycha pitilla Galileo \& Martins, 2005 is added. The three new species of Adesmus are recognized: $A$. nigrolineatus by the longitudinal black stripes on elytra; $A$. moruna by the elytra entirely black; $A$. facetus by the white belts behind the middle of the elytra and white maculae on apical quarter. Phoebemima albomaculata is characterized by the white macula on the elytral suture. Corcovado bezarki sp. nov. is distinguished by the black antennal scape and whitish flagelomeres. Canarana arguta sp. nov. has prothorax and urosternites I-IV covered by dense yellowish pubescence. Alampyris fusca sp. nov. differs from $A$. cretaria by the antenômere III longer than scape. Cariua sulphurea sp. nov. is distinguished by the urosternites covered by compact white pubescence and Ipepo dilatatus is characterized by the elytra with three carinae.
\end{abstract}

KEY WORDS. Hemilophini; new genera; new record; new species; taxonomy.

RESUMO. Novas espécies descritas e ilustradas: Adesmus nigrolineatus sp. nov. do México (Oaxaca). Da Costa Rica: $A$. moruna sp. nov. (Heredia); Corcovado bezarki sp. nov. (Guanacaste); Alampyris fuscus sp. nov. (Guanacaste), Cariua gen. nov. espécie-tipo C. sulphurea sp. nov., (Guanacaste). Da Bolívia: Phoebemima albomaculata sp. nov. (Cochabamba); Ipepo gen. nov. espécie-tipo I. dilatatus sp. nov. (Santa Cruz). Do Brasil: Adesmus facetus sp. nov. e Canarana arguta sp. nov. (Rondônia). É acrescentado novo registro na Costa Rica para Piruanycha pitilla Galileo \& Martins, 2005. As três espécies novas de Adesmus distinguem-se: $A$. nigrolineatus sp. nov. pelas faixas longitudinais de tegumento preto nos élitros; $A$. moruna sp. nov. pelos élitros inteiramente pretos; $A$. facetus pelas faixas oblíquas de pubescência branca após o meio dos élitros além das manchas do quarto apical e das epipleuras. Phoebemima albomaculata sp. nov. caracteriza-se pela mancha basal de pubescência branca dos élitros estendendo-se sobre a sutura. Corcovado bezarki sp. nov. distingue-se pelo escapo preto e antenômeros esbranquiçados. Canarana arguta sp. nov. tem o protórax e os urosternitos I a IV cobertos por densa pubescência amarelada. Alampyris fusca sp. nov. difere de $A$. cretaria principalmente pelo antenômero III mais longo que o escapo. Cariua sulphurea sp. nov. separa-se pela presença de urosternitos revestidos por pubescência branca compacta e Ipepo dilatatus sp. nov. caracteriza-se pelos élitros tri-carenados. PALAVRAS-CHAVE. Hemilophini; novas espécies; novos gêneros; novo registro; taxonomia.

Com base em material recebido de James Wappes, San Antonio (ACMS) e de Larry G. Bezark, Sacramento (LGBC), que reuniram exemplares de diversas coleções, são descritos novos táxons e faz-se novo registro. Novas espécies são descritas em Adesmus Lepeletier \& Audinet-Serville, 1825, Alampyris Bates, 1881, Canarana Martins \& Galileo, 1992, Corcovado Lane, 1973 e Phoebemima Tippmann, 1960. Dois gêneros novos são propostos: Cariaua gen. nov. e Iрери gen. nov.
Adesmus conta com 43 espécies e foi revisado por Galileo \& Martins (1999); outras doze espécies foram incluídas posteriormente e estão arroladas no catálogo de Monné \& Hovore (2006). Descrevem-se mais três espécies procedentes do México, da Costa Rica e do Brasil (Rondônia).

Phoebemima e suas cinco espécies têm distribuição na América do Sul e foram tratados por Galileo \& Martins (1996) e Martins \& Galileo (1998) que sinonimizaram Tacocha Lane, 1970 
ao gênero. As quatro espécies descritas em Tacocha foram ilustradas e identificadas através de chave por Galileo \& Martins (1996). Pela distribuição da pubescência branca, compacta no dorso dos élitros há dois grupos de espécies em Phoebemima: espécies com mancha única da base ao ápice [P. ensifera Tippmann, 1960, P. aequatoria (Lane, 1970), P. theaphia (Bates, 1881)] e espécies com três manchas individualizadas (P. antiqua (Gahan, 1889), P. teteia Galileo \& Martins, 1996)]. No último grupo, é descrita mais uma espécie.

Corcovado reúne duas espécies (Monné \& Hovore 2006) procedentes do Peru e do Brasil (Rio de Janeiro). Com a descrição de uma nova espécie, estende-se a distribuição para a América Central (Costa Rica).

Canarana foi proposto por Martins \& Galileo (1992) para transferir espécies previamente alocadas em Hilarolea Thomson, 1868. Outras espécies foram acrescidas ao gênero por Galileo \& Martins (2001, 2004), perfazendo oito e distribuídas no Peru, Bolívia, Equador, Brasil (Amazonas, Mato Grosso do Sul) e Paraguai. Nesse trabalho, descreve-se uma nova espécie procedente de Rondônia (Brasil).

Martins \& GaLileo (1991) propuseram a divisão de Lycidola Thomson, 1864 em cinco outros, todos com espécies apresentando aspecto geral liciforme, élitros expandidos na metade apical e com duas ou quatro carenas (exceto espécies de Icupima Martins \& Galileo, 1991). Ora será proposto mais um gênero, Ipepo gen. nov., da Bolívia.

Cariua gen. nov. com espécie que se assemelha a espécies de Ibitiruna Galileo \& Martins, 1997 e de Cuiciuna Galileo \& Martins, 1997 é proposto para uma espécie da Costa Rica.

Alampyris encerra 10 espécies mexicanas e centro-americanas (Monné \& Hovore, 2006) e descrevemos outra mais da Costa Rica.

As coleções citadas no texto correspondem ao American Coleoptera Museum, Coleção J. Wappes, San Antonio (ACMS); Instituto Nacional de Biodiversidad, Santo Domingo, Heredia (INBIO); Museo Noel Kempff Mercado, Santa Cruz (MNKM); Coleção Larry G. Bezark, Sacramento (LGBC); Museu de Zoologia, Universidade de São Paulo, São Paulo (MZSP); Utah State University, Logan (USUL). As dimensões são fornecidas em milímetros (mm).

\section{Adesmus nigrolineatus sp. nov.}

Fig. 1

Macho. Tegumento, em geral, amarelo-alaranjado. Antenas (exceto base do escapo) e duas faixas longitudinais em cada élitro, pretas; orla apical dos tarsômeros I e II, tarsômeros III e dois terços basais do V, castanho-escuros.

Cabeça revestida por pubescência esbranquiçada, densa; no vértice, mais alaranjada. Lado externo das mandíbulas, clípeo e orla externa do labro com pubescência esbranquiçada. Distância entre os lobos oculares superiores maior que o triplo da largura de um lobo. Estreitamentos entre os lobos oculares superiores e inferiores com única fileira de omatídios. Antenas ultrapassam o ápice elitral a partir do antenômero VIII. Escapo com tegumento alaranjado-escuro no terço basal. Pubescência esbranquiçada no terço basal do lado interno dos antenômeros II a VII.Pronoto revestido por pubescência alaranjada, densa, com áreas de pubescência esbranquiçada nos lados, visível conforme a incidência da luz. Pontuação no disco pronotal grossa, esparsa e rasa. Mesepisternos, mesepimeros e metepisternos revestidos por pubescência esbranquiçada; restante dos esternos torácicos com pubescência alaranjada. Escutelo revestido por pubescência esbranquiçada.Élitros com pubescência branca, densa, intercalada por faixas longitudinais de tegumento preto e pubescência preta, curta: uma lateral, do úmero até o quinto apical e outra paralela à sutura, dorsal, de cada lado do escutelo, sem tocar a base, até o quinto apical. Carena elitral pouco manifesta. Extremidades elitrais arredondadas.Fêmures sublineares. Urosternitos com pubescência alaranjada sedosa e os lados do I e II com áreas de pubescência esbranquiçada, densa.

Dimensões, holótipo macho. Comprimento total, 11,7; comprimento do protórax, 2,3; maior largura do protórax, 2,8; comprimento do élitro, 8,2; largura umeral, 3,7.

Material-tipo. Holótipo macho, México, Oaxaca: Tepanetapec (33 km N), 18-22.VI.1987 J. E. Wappes leg. (ACMS).

Comentários. Adesmus nigrolineatus sp. nov. distingue-se das demais pelas faixas longitudinais de tegumento preto nos élitros.

Etimologia. Latim, nigra = preto; lineatus = marcados com linhas, riscado; relativo às faixas pretas dos élitros.

\section{Adesmus moruna sp. nov.}

\section{Fig. 2}

Fêmea. Colorido geral preto exceto duas pequenas manchas no vértice e o pronoto com pubescência amareloalaranjada, esponjosa. Cabeça não abaulada no vértice, com pontos esparsos. Distância interocular dorsal igual ao triplo da largura de um lobo. Estreitamento entre os lobos oculares superiores e inferiores com duas fileiras de omatídios. Antenas não ultrapassam o ápice dos élitros.

Protórax com gibosidade lateral. Pronoto com pubescência esponjosa amarelo-alaranjada e algumas setas pretas, longas e finas nos lados.

Élitros com pontuação aparente, menos evidente no terço apical. Extremidades elitrais truncadas. Carena elitral manifesta, curva.

Fêmures lineares. Pubescência branca, densa nos lados do urosternito III e quase inteiramente no IV. Borda apical do urosternito $\mathrm{V}$ profundamente emarginada.

Dimensões, holótipo fêmea. Comprimento total, 13,2; comprimento do protórax, 2,1; maior largura do protórax, 2,8; comprimento do élitro, 10,7; largura umeral, 3,7.

Material-tipo. Holótipo fêmea, CosTa Rica, Heredia: Parque Nacional Bráulio Carrillo (Estación Barva, 2500 m) IV.1990, A. Fernandez leg., 233400-523200 (INBIO CR1000 177909).

Comentários. Adesmus moruna sp. nov. é semelhante de 

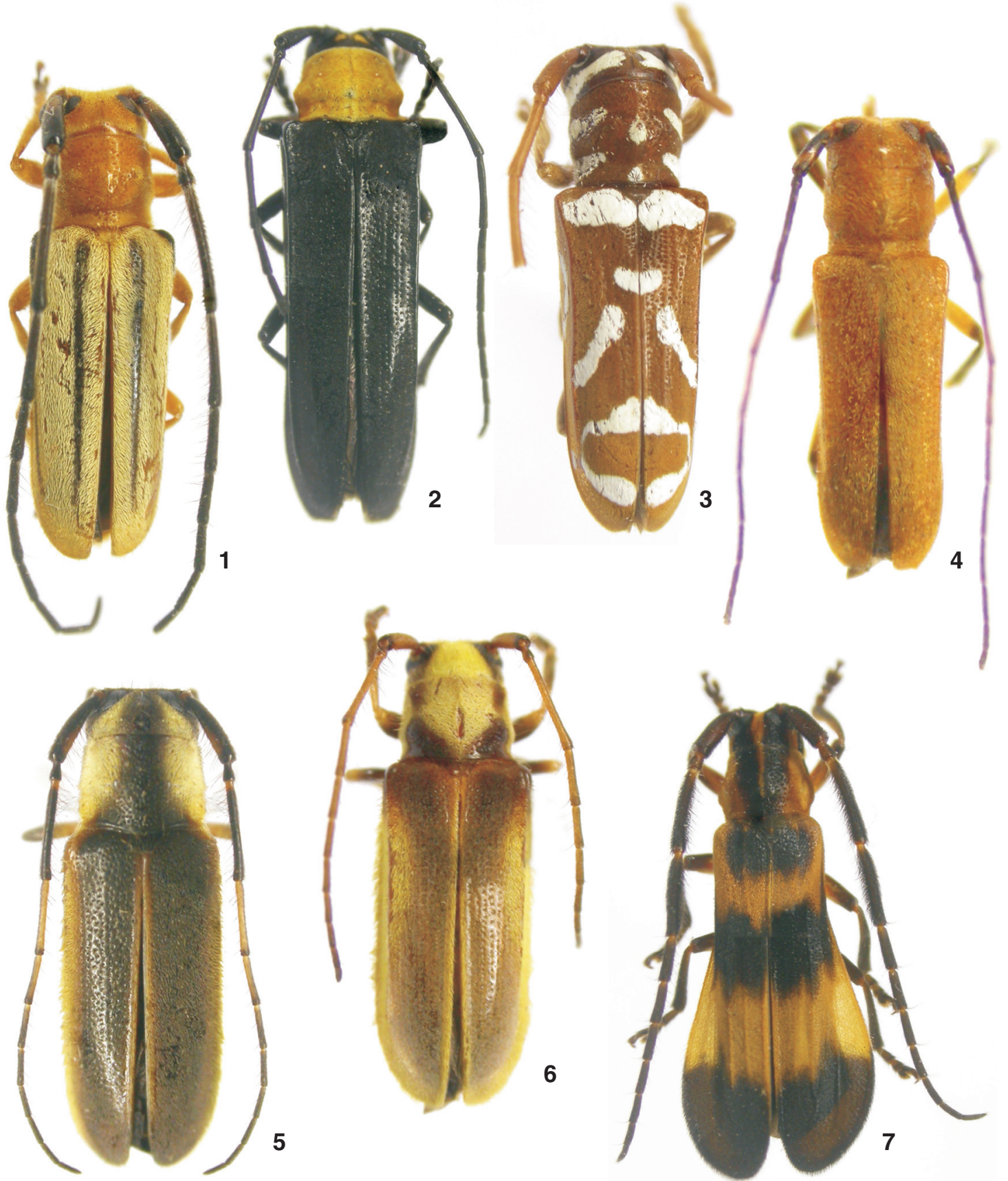

Figuras 1-7. Habitus: (1) Adesmus nigrolineatus sp. nov., holótipo macho, comprimento 11,7 mm; (2) A. moruna sp. nov., holótipo fêmea, comprimento 13,2 mm; (3) A. facetus sp. nov., holótipo macho, comprimento 12,3 mm; (4) Corcovado bezarki sp. nov., parátipo fêmea, comprimento 6,9 mm; (5) Alampyris fuscus sp. nov., holótipo macho, comprimento 8,9 mm; (6) Cariua sulphurea sp. nov., holótipo fêmea, comprimento 9,9 mm; (7) Ipepo dilatatus sp. nov., holótipo macho, comprimento 13,6 mm.

A. bisellatus (Bates, 1881) pelo padrão geral do corpo. Difere pelo pronoto inteiramente alaranjado, élitros pretos, sem faixa anteapical amarelada e pela presença de manchas de pubescên- cia branca nos urosternitos. Em A. bisellatus, o pronoto é alaranjado com manchas pretas, os élitros são pretos com faixa amarelada anteapical e os urosternitos não têm áreas de pubescência 
branca. Dentre as espécies com élitros inteiramente pretos ou acastanhados, A. moruna assemelha-se a A. urubu Galileo \& Martins, 1999 pelas extremidades elitrais subtruncadas com espículo externo. A nova espécie distingue-se dessas pelas antenas pretas, pois em A. urubu o escapo é bicolor e os antenômeros IV, V e metade do VI são amarelados.

Etimologia. Tupi, moruna = preto; alusivo ao colorido do tegumento elitral.

\section{Adesmus facetus sp. nov.}

\section{Fig. 3}

Macho. Colorido geral vermelho-alaranjado. Pubescência branca, compacta: faixa atrás dos olhos de cada lado da cabeça; duas pequenas manchas, uma no meio e outra na base do pronoto; duas faixas transversais nos lados do protórax; faixa larga no limite com o prosterno; em cada élitro: (1) mancha transversal da sutura até a carena no quinto basal; (2) pequena mancha sutural no quarto anterior; (3) faixa oblíqua da carena até quase a sutura, no meio; (4) faixa triangular, sutural, no quinto posterior; (5) faixa elíptica anteapical fundida com a anterior pelo lado da margem; (6) três manchas nas epipleuras, uma sob o úmero, uma curva no terço anterior e outra pequena ao lado da mancha apical. Pubescência branca compacta na face ventral: mesepisternos, mesepimeros, parte superior e posterior dos metepisternos, lados do metasterno e lados dos urosternitos.

Extremidades elitrais desarmadas. Pro- e mesotarsômeros III largos. Borda apical do urosternito V não emarginada.

Dimensões, holótipo macho. Comprimento total, 12,3; comprimento do protórax, 2,6; maior largura do protórax, 2,8; comprimento dos élitros, 8,6; largura umeral, 3,9.

Material-tipo. Holótipo macho, BrasIL, Rondônia: Ariquemes (62 km SE), 22-31.X.1997, W.J. Hanson leg. (USUL).

Comentários. Adesmus facetus sp. nov. assemelha-se a $A$. paradiana Galileo \& Martins, 2004 por apresentar muitas manchas pequenas de pubescência branca no tórax e nos élitros. A nova espécie difere dessa espécie previamente conhecida pelas manchas de pubescência branca: (1) duas pequenas no meio do pronoto; (2) duas faixas transversais nas partes laterais do protórax; (3) sutural no nível do terço anterior dos élitros; (4) faixas oblíquas após o meio dos élitros; além das manchas do quarto apical e das epipleuras. Em A. paradiana, o pronoto apresenta quatro pequenas manchas de pubescência branca; os lados do protórax são inteiramente cobertos pela faixa longitudinal de pubescência branca; os élitros não têm a mancha sutural no terço anterior e nem a faixa oblíqua; as epipleuras têm apenas mancha subumeral.

Etimologia. Latim, facetus = elegante; alusivo ao aspecto geral.

\section{Phoebemima albomaculata sp. nov.}

$$
\text { Fig. } 8
$$

Macho. Tegumento avermelhado a alaranjado. Pubescência amarelada, compacta, intercalada por áreas de pubescên- cia esbranquiçada: fronte; região atrás dos olhos; lados do protórax estendendo-se aos lados do pronoto; no dorso dos élitros em três manchas eqüidistantes - (1) no terço basal, recobre a sutura e prolonga-se anteriormente até o escutelo e também posteriormente, (2) subelíptica, central e dorsal, (3) elíptica e dorsal no terço apical; lados do prosterno; mesepisternos; mesepimeros, metepisternos, lados do metasterno e lados dos urosternitos I-V.Olhos bem desenvolvidos; distância entre os lobos oculares superiores subigual à metade da largura de um lobo. Antenas ultrapassam as extremidades elitrais a partir do ápice do antenômero VIII. Escapo subcilíndrico, sem curvatura interna. Protórax mais largo que longo, com lados subparalelos. Élitros com úmeros arredondados, margens paralelas e ápices arredondados. Carena elitral muito curta, apenas na região umeral. Comprimento elitral igual a 2,4 vezes a largura umeral. Fêmures lineares. Ápice dos metafêmures atinge a margem posterior do urosternito II. Metatarsômero I tão longo quanto II+III. Último urosternito com a borda apical emarginada.

Dimensões, holótipo macho. Comprimento total, 16,8; comprimento do protórax, 2,7; maior largura do protórax, 3,4; comprimento do élitro, 12,6; largura umeral, 5,2.

Material-tipo. Holótipo macho, Bolívia, Cochabamba: Villa Tunari ("on the" rio Chaparé), 16.X.1996, P.H. Sullivan leg. (MNKM).

Comentários. Phoebemima albomaculata sp. nov. apresenta, no dorso dos élitros, três manchas de pubescência branca, compacta assim como em P. antiqua (Gahan, 1889) e P. teteia Galileo \& Martins, 1996. P. albomaculata sp. nov. diferencia-se de $P$. antiqua pela mancha no terço basal dos élitros estendendose sobre a sutura; pela margem interna da mancha nos lados do pronoto sem entalhe; e de $P$. teteia pelo escutelo sem pubescência branca compacta, pelo formato da mancha de pubescência branca no terço apical dos élitros com margens anterior e posterior curvas. Em P. antiqua a mancha anterior de pubescência branca dos élitros não toca a sutura e as faixas laterais do pronoto têm as margens internas reentrantes no terço anterior. Em P. teteia o escutelo é coberto por pubescência branca e a mancha anterior do dorso dos élitros tem a margem anterior reta e a posterior oblíqua, descendente da sutura para a margem.

Etimologia. Latim, albomaculatus = manchado de branco.

\section{Corcovado bezarki sp. nov.}

Fig. 4

Colorido geral alaranjado revestido por pubescência amarelo-dourada, principalmente no pronoto. Distância entre os lobos oculares superiores igual ao dobro da largura de um lobo. Escapo avermelhado com grande mancha dorsal e ápice, pretos. Pedicelo e antenômero III, pretos. Antenômero IV com a metade basal preta e a apical, alaranjada. Antenômeros VIII a XI, pretos. Nos machos, antenômeros V e VI amarelados com ápice preto; VII amarelado com quarto apical preto. Nas fêmeas, antenômero V alaranjado, VI preto com a base alaranjada, 
VII inteiramente preto. Fêmures amarelados com o ápice preto. Tíbias pretas com o lado interno amarelado. Tarsômeros avermelhados. Tubérculos do metasterno mais evidentes nos machos que nas fêmeas.

Dimensões, holótipo e parátipo machos/parátipo fêmea. Comprimento total, 6,1-6,7/6,9; comprimento do protórax, 1,31,4/1,4; maior largura do protórax, 1,4-1,6/1,7; comprimento do élitro 4,2 e 4,7/4,9; largura umeral, 2,0-2,0/2,0.

Material-tipo. Holótipo macho, Costa Rica, Guanacaste: Rio Naranjo (3 km SE), 1-10.IX.1992, F.D. Parker leg. (USUL). Mesmos dados do holótipo: parátipo macho (MZSP); parátipo fêmea, 24-31.X.1992, F.D. Parker leg. (LGBC).

Comentários. Corcovado bezarki sp. nov. distingue-se de C. ruber (Bates, 1881) procedente do Rio de Janeiro, pelas menores dimensões, pelo colorido geral amarelado revestido por pubescência amarelo-dourada; pelo escapo preto e pelos antenômeros amarelados (metade apical do IV, V e VI-VII menos o quarto apical nos machos; metade apical do IV, V e VII menos o quarto apical, nas fêmeas); pelos fêmures não enegrecidos nos ápices; pelas tíbias pretas. Em C. ruber, o tegumento e a pubescência são avermelhados, apenas o antenômero IV tem os três quartos basais esbranquiçados, os fêmures e as tíbias são totalmente alaranjados. Em C. peruviense Lane, 1973, os antenômeros IV e V são esbranquiçados e as pernas são avermelhadas.

Etimologia. O epíteto é uma homenagem a Larry G. Bezark, California Department of Food and Agriculture, Sacramento.

\section{Piruanycha pitilla Galileo \& Martins, 2005}

Piruanycha pitilla Galileo \& Martins, 2005: 106; Monné \& Hovore, 2006: 265 (cat.).

Localidade-tipo. Costa Rica, Guanacaste: Santa Cecilia ( 9 km S Estación Pitilla, 700 m).

Material examinado. Costa RicA, Guanacaste: R. Naranjo (3 km SE), macho, 11-20.VII.1992, F.D. Parker leg. (LGBC); fêmea, 16-31.X.1992, F.D. Parker leg. (LGBC); fêmea, 1331.VII.1993, F.D. Parker leg. (MZSP).

\section{Canarana arguta sp. nov.}

\section{Fig. 9}

Fêmea. Cabeça com tegumento preto revestido por densa pubescência branco-amarelada. Escapo castanhoavermelhado. Antenômero III, preto; IV e V laranja-acastanhados; VI com a base laranja-acastanhada e, no ápice, preto; VII$\mathrm{XI}$, pretos.

Protórax com tegumento alaranjado recoberto por densa pubescência amarelada. Lados do protórax com gibosidade no nível do terço posterior. Pronoto com gibosidade centro-posterior. Escutelo revestido por pubescência branco-amarelada. Élitros castanho-claros com friso sutural revestido por pubescência amarelada. Extremidades dos élitros truncadas e com dois espículos: um no ângulo marginal e outro no ângulo sutural. Esternos torácicos castanho-avermelhados. Mesepisternos e urosternitos
I a IV revestidos por densa pubescência branco-amarelada. Pernas castanho-avermelhadas.

Dimensões, holótipo fêmea. Comprimento total, 10,0; comprimento do protórax, 1,9; maior largura do protórax, 2,6; comprimento do élitro, 7,2; largura umeral, 3,0.

Material-tipo. Holótipo fêmea, Brasil, Rondônia: Ariquemes (62 km SE), 22-31.X.1997, W.J. Hanson leg. (LGBC).

Comentários. Canarana arguta sp. nov. assemelha-se, pelo colorido elitral, a C. roseicollis Galileo \& Martins, 2004 descrita da Bolívia. Difere dessa espécie pelo protórax e pelos urosternitos I a IV cobertos por densa pubescência amarelada. Em $C$. roseicollis os lados anteriores do protórax apresentam grande mancha de pubescência rósea e a pilosidade amarelada reveste os urosternitos II a IV.

Etimologia. Latim, arguta = claro; alusivo ao colorido dos élitros.

\section{Alampyris fuscus sp. nov.}

Fig. 5

Macho. Cabeça com tegumento preto; revestida por pubescência branco-amarelada, densa, na fronte, nas genas e nas regiões atrás dos olhos. Antenas pouco mais longas que o corpo. Margem interna do escapo e dos flagelômeros basais com franja de pêlos longos Escapo preto com mancha avermelhada no lado interno. Pedicelo e antenômeros IX a XI pretos. Antenômeros IV e V alaranjados com anel apical preto. Antenômeros III e VIVIII pretos com anel basal alaranjado. Antenômero III mais longo que o escapo. Protórax preto; lados do pronoto revestidos por densa pubescência amarelo-esbranquiçada. Partes laterais do protórax cobertas por pubescência branco-amarelada e com faixa preta no limite com o prosterno. Escutelo preto. Élitros pretos com faixa alaranjada, longitudinal sobre a sutura; a cada lado faixa longitudinal, alaranjada, revestida por densa pubescência amarelada e longa; essa faixa, na metade basal, envolve os úmeros, mas não cobre a declividade lateral nem as epipleuras. Extremidades elitrais arredondadas. Pro- e mesofêmures amarelados com terço apical preto; metafêmures pretos com base e lado interno amarelo-alaranjados. Tíbias pretas com base amarelada. Base dos tarsômeros I, II e V amarelada. Face ventral do corpo preta, mais avermelhada na região posterior do metasterno e na borda dos urosternitos I-IV. Último urosternito com entalhe central.

Dimensões, holótipo. Comprimento total, 8,9; comprimento do protórax, 1,8; maior largura do protórax, 2,3; comprimento dos élitros, 6,5; largura umeral, 2,9.

Material-tipo. Holótipo macho, Costa Rica, Guanacaste: Rio Naranjo (3 km SE), 9-12.VII.1993, F.D. Parker leg. (LGBC).

Comentários. Alampyris fuscus sp. nov. é semelhante a $A$. cretaria Bates, 1885 e a A. quadricollis Bates, 1881. A nova espécie distingue-se de $A$. cretaria principalmente pelo antenômero III mais longo que o escapo; em $A$. cretaria tem o mesmo comprimento. Separa-se de A. quadricollis pela pubescência longa da faixa marginal. Em A. quadricollis a pilosidade da faixa é curta. Etimologia. Latim, fuscus $=$ escuro. 


\section{Cariua gen. nov.}

Espécie-tipo, Cariua sulphurea sp. nov.

Cabeça moderadamente convexa no vértice. Região entre os tubérculos anteníferos sem depressão. Olhos normais, lobos superiores ligados aos inferiores por duas fileiras de omatídios. Lobos oculares superiores tão distantes entre si quanto o quádruplo da largura de um lobo. Antenas mais curtas que o corpo, nas fêmeas atingem o terço apical dos élitros. Escapo cilíndrico, tão longo quanto a metade do antenômero III, sem cicatriz. Flagelômeros com franja de pêlos esparsos na margem interna. Antenômero III com quase o dobro do comprimento do IV; antenômeros IV a XI com comprimentos decrescentes.

Protórax mais largo que longo; partes laterais com gibosidade discreta no nível do terço posterior.

Élitros com única carena; franja de pêlos nas margens; lados subparalelos; extremidades arredondadas e desarmadas. Ápices dos metafêmures atingem o ápice do urosternito II. Dente interno das garras tarsais com a metade do comprimento do dente externo. Urosternito IV revestido por pilosidade compacta.

Comentários. Pelas antenas com franja esparsa, protórax sem gibosidade manifesta nos lados, élitros com ápices arredondados e margens providas de pêlos longos, Cariua gen. nov., assemelha-se a Cuiciuna Galileo \& Martins, 1997 e a Ibitiruna Galileo \& Martins, 1997. Cariua gen. nov. difere pelo aspecto geral compacto, pelas antenas curtas e pela presença de urosternitos revestidos por pubescência compacta. Além disso, separa-se de Cuiciuna pelo dente interno das garras tarsais curto (em Cuiciuna é o dente interno é quase tão longo quanto o externo e distingue-se de Ibitiruna pelo antenômero III com o dobro do comprimento do escapo; em Ibitiruna o antenômero III tem comprimento subigual ao do escapo.

Etimologia. Tupi, cariua $=$ poderoso.

\section{Cariua sulphurea sp. nov.}

Fig. 6

Fêmea. Cabeça revestida por densa pubescência amarelada, menos numa faixa longitudinal atrás dos olhos. Antenas laranja-acastanhadas com os antenômeros apicais gradualmente mais escurecidos.Pronoto com a região central revestida por pilosidade branco-amarelada densa; essa região tem lados subparalelos até o meio do pronoto e, posteriormente, convergentes para o centro. Partes laterais do protórax revestidas por pubescência branco-amarelada.

Élitros com tegumento castanho-avermelhado; friso sutural, epipleuras e margens apicais cobertas por pilosidade amarelada e longa.Fêmures amarelados com anel anteapical acastanhado. Tíbias pretas com a base amarelada. Meso- e metatarsômeros I e II cobertos por pubescência esbranquiçada.

Dimensões, holótipo fêmea. Comprimento total, 9,9; comprimento do protórax, 1,8; maior largura do protórax, 2,0; comprimento do élitro, 7,2; largura umeral, 3,2.

Material tipo. Holótipo fêmea, Costa Rica, Guanacaste:
Rio Naranjo (3 km SE), 16-29.II.1992, F.D. Parker leg. (USUL). Etimologia. Latim, sulphureus $=$ cor de enxofre.

\section{Ipepo gen. nov.}

Espécie-tipo, Ipepo dilatatus sp. nov.

Lobos oculares superiores tão distantes entre si quanto o dobro da largura de um lobo; lobos oculares inferiores mais longos que as genas. Antenas com 11 artículos. Escapo subcilíndrico, com dois terços do comprimento do antenômero III. Escapo, pedicelo e antenômeros III e IV densamente pubescentes e com franja de pêlos longos na margem interna, mais densa nos antenômeros III e IV. Antenômero III apenas mais longo do que o IV (2,5 mm e 2,3 mm, respectivamente); antenômeros seguintes gradativamente mais curtos. Protórax com gibosidade arredondada no terço basal. Processo prosternal muito estreito entre as procoxas. Processo mesosternal com um quarto da largura de uma mesocoxa. Élitros expandidos a partir do terço basal; extremidades arredondadas; três carenas dorsais completas. Último urosternito entalhado no centro da borda apical.

Comentários. Iреро gen. nov. apresenta caracteres também encontrados em Lycidola Thomson, 1864 e Apeba Martins \& Galileo, 1991: flagelômeros III e IV com pilosidade densa, diferenciada dos antenômeros seguintes, antenômero III reto e mais longo que o escapo, élitros com mais de uma carena, expandidos na metade apical e com ápices arredondados. Ipepo gen. nov. Distingue-se dos dois outros gêneros pela gibosidade lateral do protórax bem desenvolvida; pelos élitros com três carenas; pela fórmula antenal, a soma do comprimento de III+IV não ultrapassa a soma de V-XI. Em Lycidola os antenômeros VXI em conjunto são mais longos que III+IV, os élitros são expandidos a partir do terço basal e com quatro carenas. Em Apeba o antenômero III tem o triplo do comprimento do IV e é mais longo que IV-XI em conjunto, os élitros são expandidos desde a base e dorso com duas carenas.

Etimologia. Tupi, ipepo = asa; alusivo aos élitros expandidos.

\section{Ipepo dilatatus sp. nov.}

\section{Fig. 7}

Macho. Cabeça com tegumento e pubescência pretos exceto fronte, genas e faixas atrás dos lobos oculares superiores, de cada lado da sutura coronal, no vértice e no occipício com tegumento amarelado revestido por pubescência amarelo-alaranjada, mais esbranquiçada nas genas e na área anteclipeal. Antenas pretas, exceto escapo mais avermelhado na face dorsal; anel basal dos antenômeros III-IX, amarelados. Antenas tão longas quanto o corpo. Antenômero III o mais longo, comprimento dos seguintes gradativamente menor, antenômeros V-XI em conjunto mais longos que III+IV.

Protórax preto com faixas de pubescência amarelada densa nos lados do pronoto e em estreita faixa central que não toca a margem posterior; mancha de pubescência esbranquiçada a cada lado do pronoto, na metade basal. Pontos grossos e

Revista Brasileira de Zoologia 25 (3): 547-554, September, 2008 

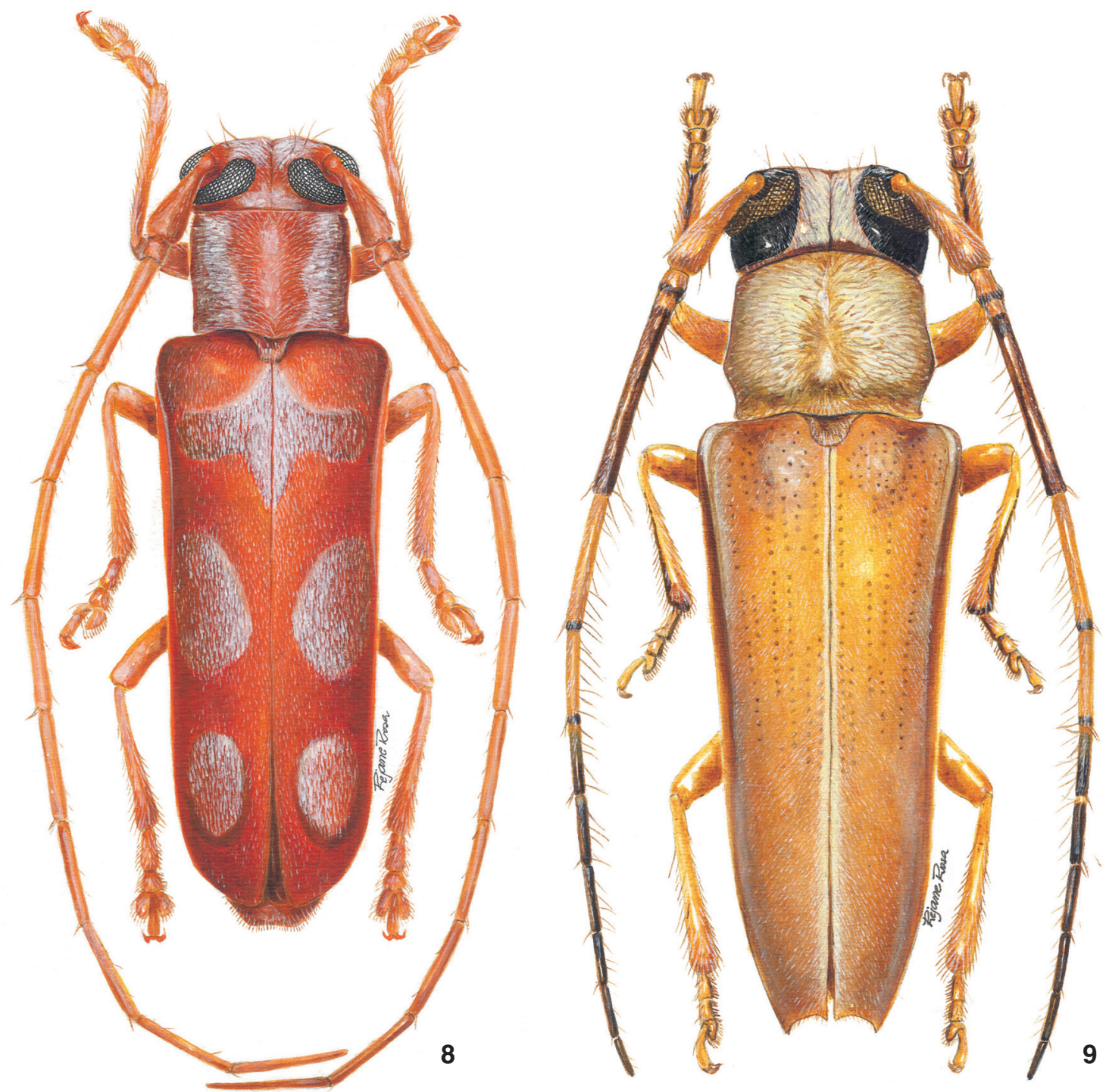

Figuras 8-9). Habitus: (8) Phoebemima albomaculata sp. nov., holótipo macho, comprimento 16,8 mm; (9) Canarana arguta sp. nov., holótipo fêmea, comprimento $10,0 \mathrm{~mm}$.

esparsos nas áreas escuras, exceto na gibosidade central do pronoto. Lados do protórax com gibosidade desenvolvida. Disco do pronoto com gibosidade discreta no centro. Escutelo preto com pequena área central junto à margem anterior com tegumento avermelhado.

Élitros amarelados com quatro áreas pretas: (1) na região circum-escutelar, (2) faixa transversal, larga, com bordas irregulares antes do meio, (3) duas faixas estreitas prolongadas até os úmeros na declividade lateral do terço basal e (4) no quarto apical. Três carenas longitudinais evidentes, duas dorsais e uma na declividade lateral; entre a central e a lateral, carena curta, inconspícua, unida à central no quarto apical.

Face ventral com tegumento preto exceto prosterno, mesosterno, centro do metasterno, centro dos urosternitos, coxas, base dos fêmures e base das protíbias, amareloalaranjados.

Dimensões, holótipo macho. Comprimento total, 13,6; comprimento do protórax, 2,0; maior largura do protórax, 2,8; comprimento do élitro, 10,3; largura umeral, 3,2; maior largura dos élitros, 5,5.

Material-tipo. Holótipo macho, Bolívia, Santa Cruz, Reserva Nacional de Potrerillo del Guenda $\left(17^{\circ} 40,26^{\prime} \mathrm{S}, 63^{\circ} 27,43^{\prime} \mathrm{W}\right.$, 400 m), 16-21.X.2006, Nearns, Wappes \& Eya leg., "beating" (MNKM).

Etimologia. Latim, dilatatus = dilatado; alusivo aos élitros alargados.

Revista Brasileira de Zoologia 25 (3): 547-554, September, 2008 


\section{AGRADECIMENTOS}

A James Wappes (ACMS), a Larry G. Bezark (LGBC) e a F.T. Hovore (in memoriam) pelo envio de material para estudo. À Rejane Rosa pelas ilustrações a cores e a Eleandro Moysés pelas imagens digitais, ambos do Museu de Ciências Naturais, Fundação Zoobotânica do Rio Grande do Sul.

\section{LITERATURA CITADA}

Galileo, M.H.M. \& U.R. Martins. 1996. Revisão do gênero Tacocha Lane, 1970 (Coleoptera, Cerambycidae, Lamiinae, Hemilophini). Revista Brasileira de Entomologia 40 (2): 233-236.

Galileo, M.H.M. \& U.R. Martins. 1999. O gênero Adesmus (Coleoptera, Cerambycidae, Lamiinae, Hemilophini). Iheringia, Série Zoologia, 86: 77-116.

Galileo, M.H.M. \& U.R. Martins. 2001. Novas espécies de Lamiinae (Coleoptera, Cerambycidae) neotropicais. Iheringia, Série Zoologia, 90: 59-70.

Submitted: 22.IV.2008; Accepted: 11.IX.2008.

Editorial responsibility: Gabriel Mejdalani
Galileo, M.H.M. \& U.R. Martins. 2004. Novos táxons em Hemilophini (Coleoptera, Cerambycidae) com única carena elitral. Iheringia, Série Zoologia, 94 (4): 381-388.

Galileo, M.H.M. \& U.R. Martins. 2005. Contribuição aos Hemilophini da Costa Rica (Coleoptera, Cerambycidae, Lamiinae). Papéis Avulsos de Zoologia, 45 (10): 103-109.

Martins, U.R. \& M.H.M. Galileo. 1991. Subdivisão do gênero Lycidola Thomson, 1864 (Hemilophini). Revista Brasileira de Entomologia 35(3): 553-565.

Martins, U.R. \& M.H.M. Galileo. 1992. Divisão do gênero Hilarolea Thomson, 1868 (Coleoptera, Cerambycidae, Lamiinae, Hemilophini). Revista Brasileira de Entomologia 36 (2): 437-447.

Martins, U.R. \& M.H.M. Galileo. 1998. Novas sinonimias e novos táxons em Cerambycidae (Coleoptera) neotropicais. Revista Brasileira de Zoologia 15 (1): 47-58.

Monné, M.A. \& F.T. Hovore. 2006. Checklist of the Cerambycidae, or longhorned wood-boring beetles, of the Western Hemisphere. Rancho Dominguez, Bioquip, 394p. 